\title{
TOR REFERENCE
}

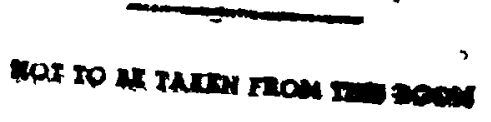

\section{Viscous Computation of a Space Shuttle Flow Field}

Denny S. Chaussee, Yehia M. Rizk and Pieter G. Buning

\section{LIBRARY COPY \\ ? ? $? 1984$}

LANGLEY RESEARCH ZENTER LIBRARY, NASÂ HAMPTON, VIRGINIA 
NASA Technıcal Memorandum 85977

\section{Viscous Computation of a Space Shuttle Flow Field}

Denny S Chaussee

Pieter G Bunıng, Ames Research Center, Moffett Fıeld, Calıfornıa

Yehıa M Rızk, Informatıcs General Corporatıon, 1121 San Antonıo Road, Palo Alto, Calıfornı

\section{N/Sก}

National Aeronautics and

Space Admınıstratıon 


\section{S. Chaussee, Y. M. Rizk, and P. G. Buning \\ NASA Ames Research Center \\ Moffett Field, CA 94035 USA}

\section{INTRODUCTION}

Recent research efforts [1-3] have confirmed the ability of the "parabolized" Navier-Stokes (PNS) codes to predict accurately and rapidly the aerothermodynamics of the actual Space Shuttle orbiter up to an axial station that is $50 \%$ of the overall length. This corresponds to a location where the strake ends and the $45^{\circ}$ swept wing begins. In the past, the geometry of the Orbiter usually has been modified [4-7] such that a solution over the complete body was possible. These modifications take the form of changing the sweep angle of the wing, removing the canopy, and altering the lee of the body so that the cross section is composed of two elliptical shapes. In one instance [8], an inviscid solution was obtained for the complete orbiter. In order to perform this calculation, a "fix" had to be used in the vicinity of the bowshock/wing-shock interaction region. Physically, what occurs is a region of embedded subsonic flow owing to the bow-shock/wing-shock interaction which causes the resulting coalescing shock wave to be more normal to the flow for a short streamwise distance. Since the above inviscid procedure was a marching code, it failed when the Mach number in the marching direction became subsonic.

A viscous numerical procedure is described, to compute the flow over the Shuttle. Results are presented that demonstrate the capability of the method. Obtainment of these results requires the use of two computer codes. A PNS code $[9,10]$ is used to 'obtain the solution up to the bow-shock/wing-shock interaction region, and an unsteady continuation code is used for the region after the shock interaction. The unsteady Navier-Stokes code [11] is also used to obtain the blunt-body starting solution. Only results from the marching code will be presented. For the flow conditions calculated, that is, $\mathrm{M}_{\infty}=7.9, \alpha=25^{\circ}, \mathrm{T}_{\text {wall }}=540^{\circ} \mathrm{R}, \mathrm{Re}_{\mathrm{L}}=60,728 /$ in., 1aminar or turbulent, the PNS code has been marched up to an $X / L=0.7$ which is where the bow-shock/w1ngshock interaction region occurs. In this work, $L$ refers to the length of the vehıcle.

\section{COMPUTATIONAL TECHNIQUE}

The PNS equations are obtained from the complete Navier-Stokes equations by neglecting the unsteady terms and the streamwse viscous derivative terms. The complete details of all the terms and derivations can be found in Ref. 12 .

In the present formulation, $\xi$ (the marching direction in computational space) is a function of $x$ only (axis-normal marching planes). The governing equations are hyperbolic-parabolic in this $\xi$-direction if the inviscid part of the flow field is supersonic, if there is no streamise (axia1) separation, and if the pressure gradient in the viscous region near the wall is treated correctly. However, the system of equations still allows for the separation in the crossflow plane $(n-\zeta)$. 
The present PNS code uses the Beam-Warming implicit algortthm to update the interior of the region and characteristic, $1 \mathrm{mpliclt,}$ spatially second-order-accurate boundary conditions at the outermost shock wave. An elliptic grid generator of the type developed by Steger and Sorenson [13] and further specialized to wing bodies by Rai et al. [10] is used to generate the grid for the calculations.

If the conditions in a particular region are such that the marching procedure is Invalidated, the unsteady Navier-Stokes (UNS) code is used for these regions. In calculating the flow over the Space Shuttle, one such region occurs in the vicinity of the bow-shock/wing-shock interaction (a pocket of subsonic flow is encountered).

The complete details of the UNS code can be found in Ref. 11. The UNS code is extremely versatile and relatıvely easy to use. It uses either a Beam-Warming implicit algorithm or a hybrid scheme due to Rizk and Chaussee [11]. The outer shock wave is elther fitted or captured. Usually the initial guess is furnished by the PNS code, which is modified in some manner to march through regions where it would not march before. This procedure is acceptable, since the unsteady code takes this reasonable guess and iterates in time until a steady-state solution is obtalned.

The domain of this unsteady calculation encompasses the subsonic flow. The outflow boundary consists entirely of supersonıc axial flow in the inviscid part of the flow field. This permits the PNS code, which is more efficient, to continue marching from this point.

\section{RESULTS}

Numerical results have been obtained for the following wind-tunnel conditions: $\mathrm{M}_{\infty}=7.9, \alpha=25^{\circ}, \mathrm{T}_{\text {wall }}=540^{\circ} \mathrm{R}, \mathrm{Re}_{\mathrm{L}}=60,728 / \mathrm{in}$. turbulent flow. For this calculation, the Shuttle surface coordinates were obtained from Rockwell-International Corporation. The current geometry consists of the complete Shuttle; the canopy, OMS pods, and the vertical stabllızer are included.

The three-dimensional blunt-body code orıginally developed by Kutler et al. [14] was used to obtain the blunt-nose solution which creates the necessary starting planes for the PNS code at $X / L=0.0522$. Th1s solution was then marched downstream using the elliptic grid generator to construct the grid between the body and the fitted outermost shock wave. The grid consisted of either 61 or 121 points in the meridional direction and 45 geometrically stretched radial points. An example of the grid at an $X / L=0.66$ is shown in F1g. 1. The outermost grid line 1s the bow wave, which is fitted using an implicit technique.

The pressure contours in the region of the canopy are sresented in Figs. 2 and 3 . In F1g. 2, the contours on the lee pitch plane of symmetry vetween $\mathrm{X} / \mathrm{L}=0.067$ and $\mathrm{X} / \mathrm{L}=0.4$ are shown. In the canopy region, the coalescence of contours details the canopy shock wave followed by an expansion wave on the lee of the Shuttle. The contours for a cross section at an $X / L=0.2$ are presented in Fig. 3. The canopy shock is once again viewed at the point on the lee where the pressure contours 
coalesce. The expansions which are visible on the windward are due to discontinuities in geometry.

The Mach number contours at an $\mathrm{X} / \mathrm{L}=0.66$ are presented in F1g. 4. The main features are the wing shock and the crossflow shocks on the wing and upper body, respectively. These are denoted by the coalescence of the Mach contours.

In Fig. 5, the crossflow velocity vectors are presented at an $\mathrm{X} / \mathrm{L}=0.66$. Two interesting features seen in this figure are the recirculation region in the wingbody juncture and the lee vortex.

The density contours in the vicinuty of the wing tip at an $X / L=0.667$ are shown in Fig. 6. The wing shock and the bow shock have interacted as characterized by the bulge in the outer boundary. This is due to the wing shock becoming the outermost surface, w1th the bow shock being captured. The bow shock appears as the coalescence of the density contours near the outer surface.

By numerically simulating 011 flow on the surface of the vehicle, as in Fig. 7, many interesting features are observed. The lines of separation on both the strakewing and the lee of the body are evident by the coalescence of the numerical oil flow. The reattachment line is visible on the Shuttle as a series of oll-flow lines diverging toward the separation lines.

The computer-generated particle paths of Fig. 8 exhibit the same trends in the flow field that are visible on the Shuttle surface via the oll flow. Specific features are the vortices on the lee which are due to the strake-wing. At this angle of attack, the vortices that are generated on the wing impact on the OMS pod.

IV. SUMMARY

A procedure has been presented for calculating the flow over vehicles that have embedded regions of subsonic flow in the inviscid part of the flow field. A PNS marching code is used to obtain the solution up to the bow-shock/wing-shock interaction region. In this interaction region, the UNS code can be employed since the region has a pocket of subsonic flow. Currently, only the results for the marching code up to an $\mathrm{X} / \mathrm{L}=0.667$ are 1 ncluded. In the future, the results for the bowshock/wing-shock region will be avallable.

\section{REFERENCES}

1. Venkatapathy, E., Rakıch, J. V , and Tannehı11, J. C., "Numerical Solution of Supersonic Viscous Flow over Blunt Delta Wings," AIAA Paper 82-0028, 1982.

2. Prabhu, D. K. and Tannehil1, J. C., "Numerical Solution of Space Shuttle Orbiter Flow Field Including Real Gas Effects," ALAA Paper 84-1747, 1984.

3. Balakrishnan, A., "Computation of Viscous Real Gas Flow Field for the Space Shuttle Orbiter," AIAA Paper 84-1748, 1984.

4. L1, C. P., "Application of an Implicit Technique to the Shock-Layer Flow Around General Bodies," AIAA Journal, Vol. 20, 1982, p. 175.

5. Szema, K. Y., Griffith, B. J., Maus, J. R., and Best, J. T., "Lamınar Viscous Flow Field Prediction of Shuttle-like Vehicle Aerodynamics," AIAA Paper 83-0211, 1983.

6. Werlmuenster, K. J., "H1gh Angle of Attack Inviscld Flow Calculations Over a Shuttle-1ike Vehıcle with Comparısons to Flight Data," AIAA Paper 83-1798, 1983. 
7. Weilmuenster, K. J. and Hami1ton, H. H., "Calculations of Inviscid Flow Over Shuttle-like Vehicles at High Angles of Attack and Comparisons with Experimental Data," NASA TP-2103, 1983.

8. Chaussee, D. S., Kutler, P., and Holtz, T., "Inviscid Supersonic/Hypersonic Body Flow Field and Aerodynamics from Shock-Capturing Technique Calculations," Journal of Spacecraft \& Rockets, Vo1. 13, 1976, pp. 325-331.

9. Rai, M. M. and Chaussee, D. S., "New Implicit Boundry Procedures: Theory and Applications," AIAA Paper 83-0123, 1983.

10. Rai, M. M., Chaussee, D. S., and Rizk, Y. M., "Calculation of Viscous Supersonic Flows over Finned Bodies," AIAA Paper 83-1667, 1983.

11. Rizk, Y. M. and Chaussee, D. S., "Three-Dimensional Viscous-Flow Computations Using a Directiona1ly Hybrid Implicit-Explicit Procedure," AIAA Paper 83-1785, 1983.

12. Schiff, L. B. and Steger, J. L., "Numerical Simulation of Steady Supersonic Viscous Flow," AIAA Paper 79-0130, 1979.

1.3. Steger, J. L. and Sorenson, R. L., "Automatic Mesh-Point Clustering Near a Boundary in Grid Generation with E1liptic Partial Differential Equations," Journal of Computational Physics, Vo1. 33, 1979, pp. 405-410.

14. Kutler, P., Pedelty, J. A., and Pulliam, T. H., "Supersonic Flow Over ThreeDimensiona1 Ablated Nosetips using an Unsteady Implicit Numerical Procedure," AIAA Paper 80-0063, 1980.

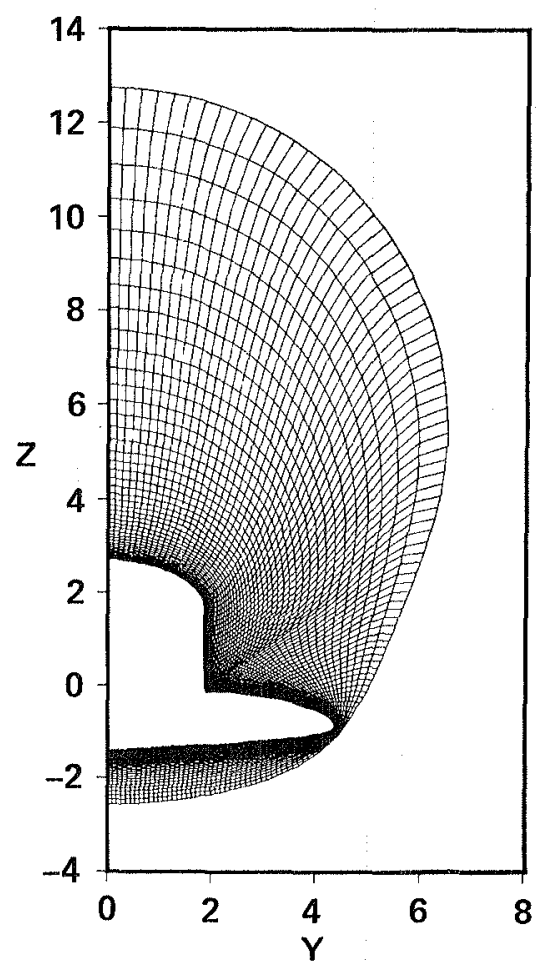

Fig. 1 E1liptic grid at $X / L=0.66$ :

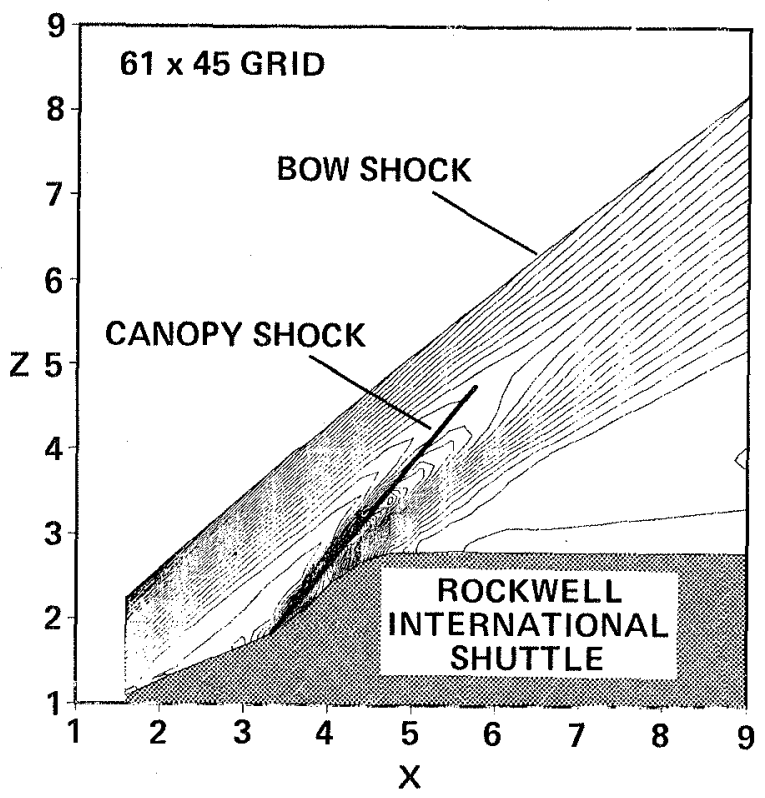

Fig. 2 Pressure contours in the lee pitch plane of symmetry. 


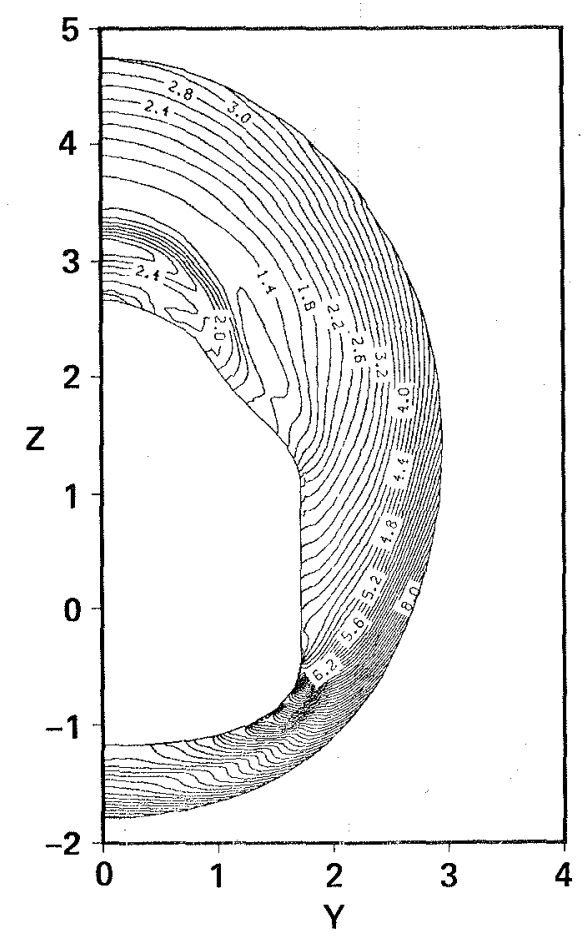

Fig. 3 Pressure contours at $\mathrm{X} / \mathrm{L}=0.2$.

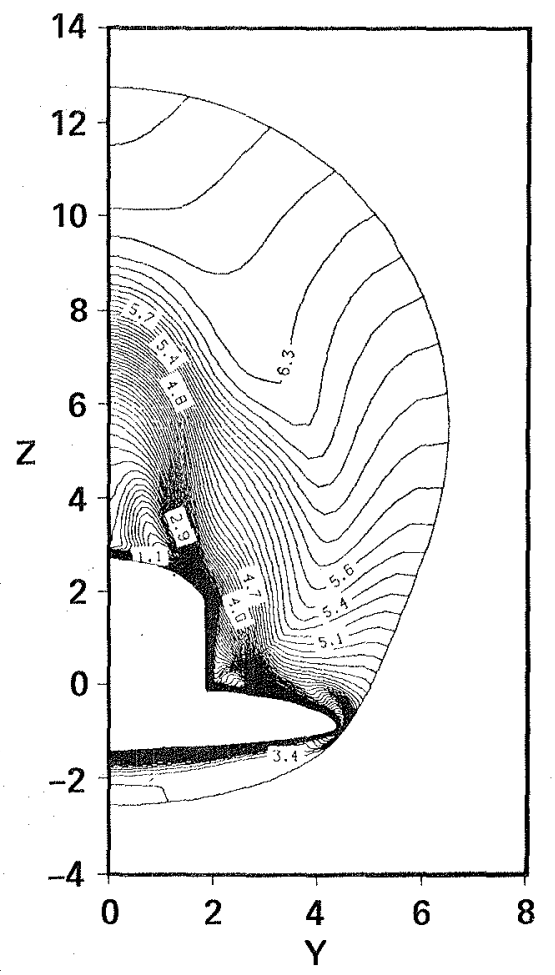

Fig. 4 Mach contours at $X / L=0.66$.

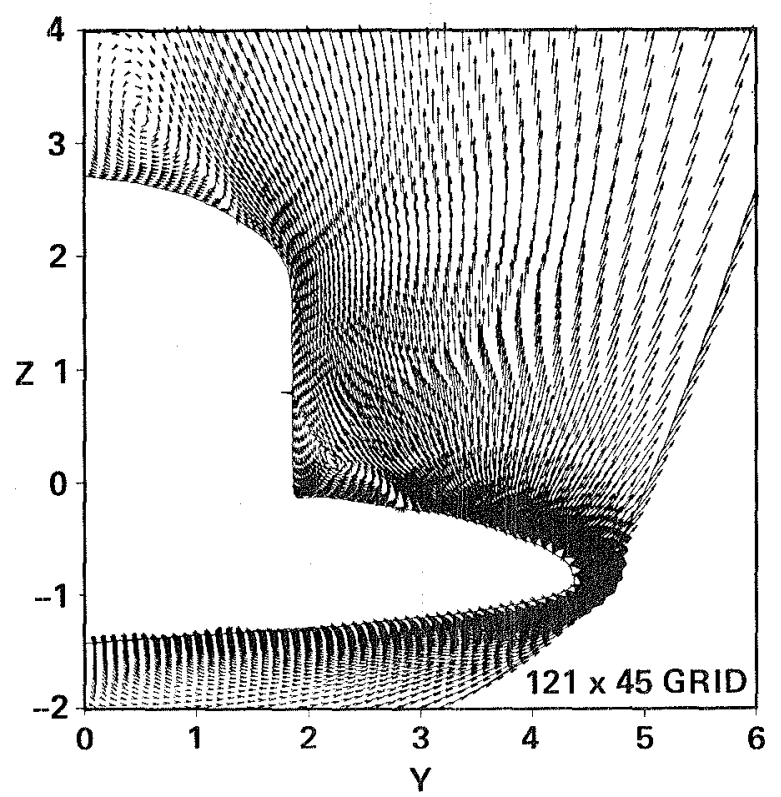

Fig. 5 Crossflow velocity vectors at $\mathrm{X} / \mathrm{L}=0.66$.

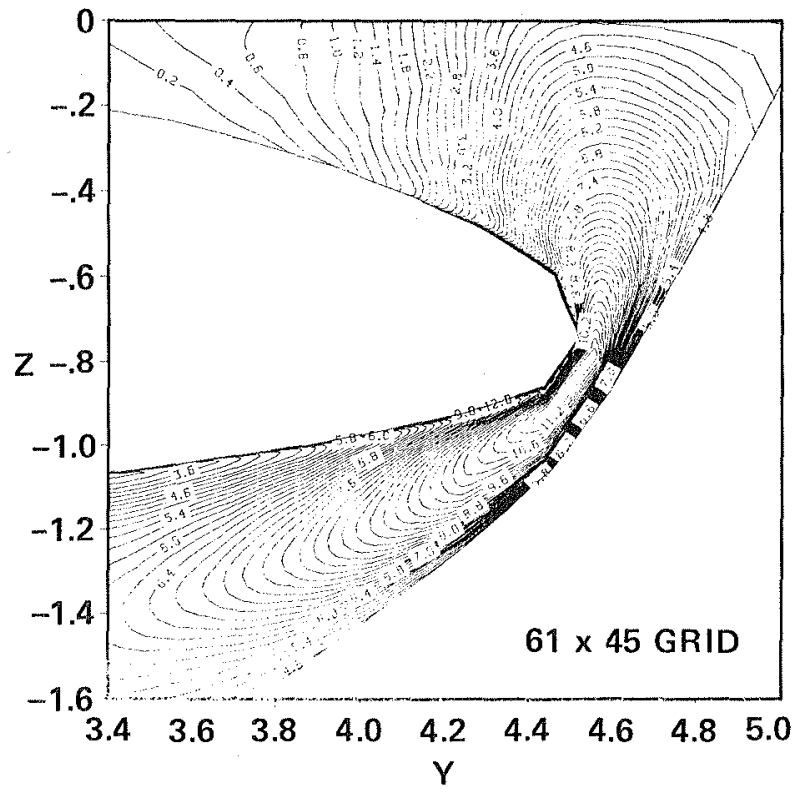

Fig. 6 Density contours near the wing tip at $\mathrm{X} / \mathrm{L}=0.667$. 
$61 \times 45$ GRID

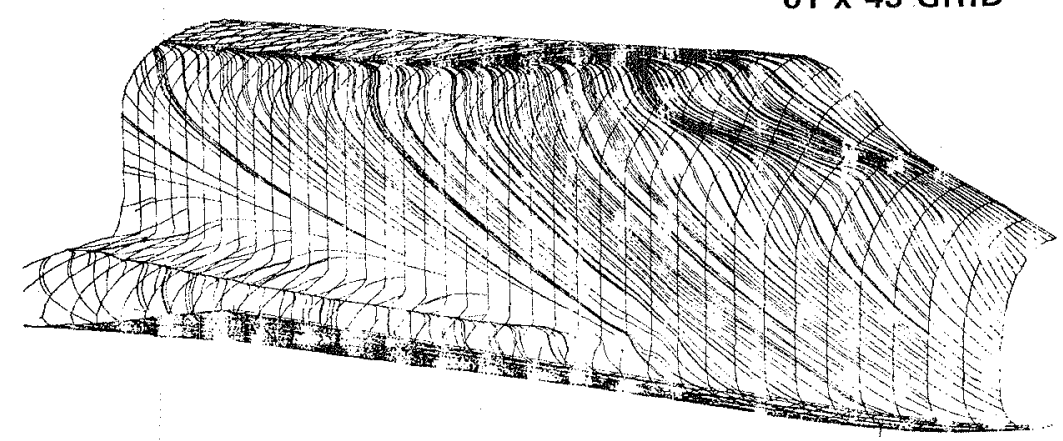

Fig. 7 Computational oil flow on the Shuttle surface up to $X / L=0.66$.

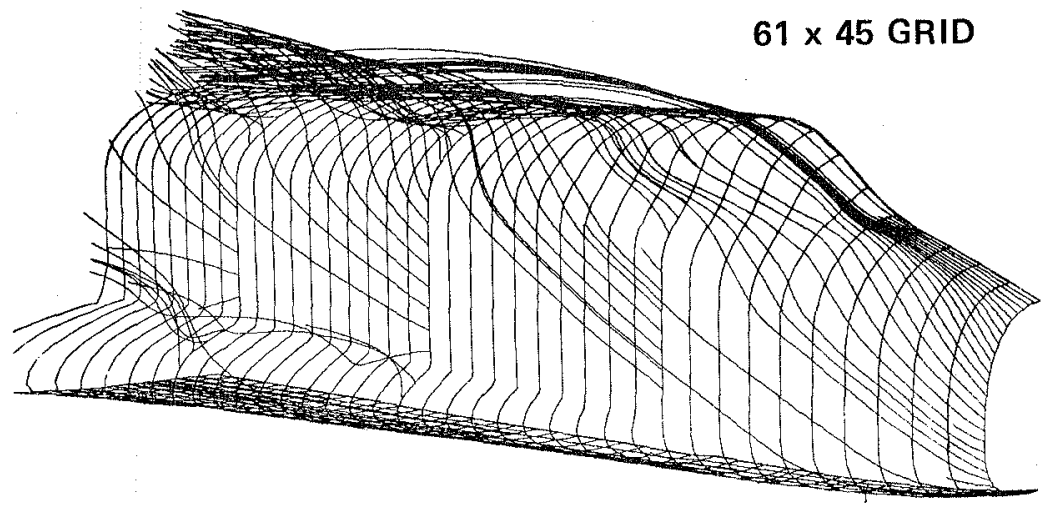

Fig. 8 Computational particle paths up to $X / L=0.66$. 


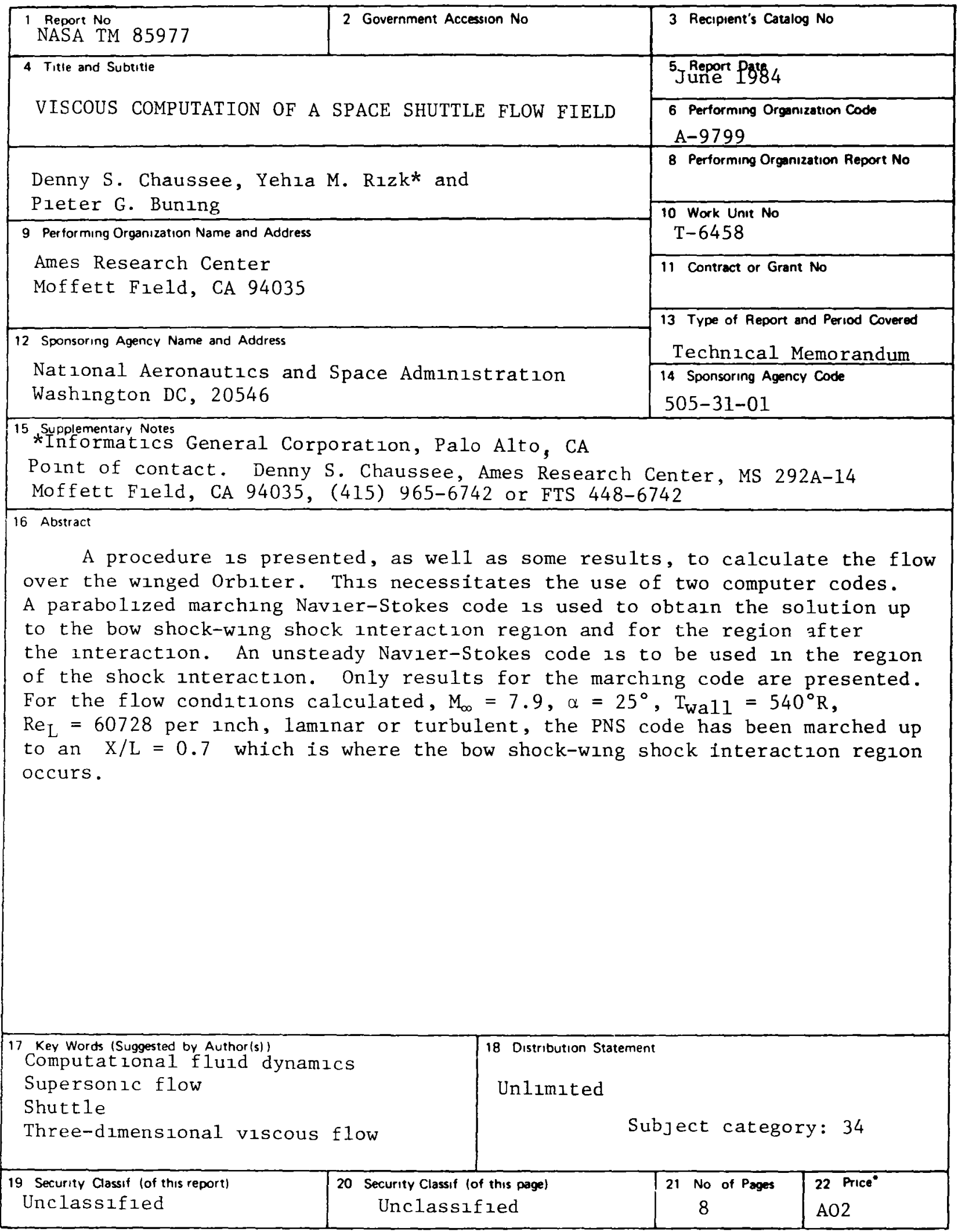

- For sale by the National Technical Information Service Springfield Virginı 22161 
End of Document 